\title{
The clinical and laboratory course of polymyalgia rheumatica/giant cell arteritis after the first two months of treatment
}

\author{
V Kyle, B L Hazleman
}

\begin{abstract}
Objectives-To examine the clinical course of polymyalgia rheumatica (PMR) and giant cell arteritis (GCA) in a prospective study, after the initial two months.

Methods-Seventy four patients with PMR/GCA were followed for a median of 60 weeks. Detailed clinical and laboratory records were made on each visit.

Results-Twenty per cent of patients with PMR developed GCA and $24 \%$ of patients with GCA developed PMR from the onset of symptoms. After two months, most patients experienced at least one relapse. Relapses and persistence of abnormal symptoms and signs were most common in patients with both PMR and GCA and least common in those with GCA alone. Relapses were most common in the first year and $54 \%$ occurred in association with steroid reduction. Major complications were rare. Laboratory parameters and temporal artery histology were not helpful in predicting relapse. Only $24 \%$ of patients were able to stop steroid treatment after two years.
\end{abstract}

Conclusions-Clinicians should consider more frequent review in patients at times of steroid reduction and especially within the first six months of treatment.

(Ann Rheum Dis 1993; 52: 847-850)

The earliest case reports of polymyalgia rheumatica (PMR) and giant cell arteritis (GCA) emphasised that patients made a full recovery. ${ }^{12}$ Before corticosteroid therapy, however, patients with PMR were reported to have symptoms from three months to 35 years, ${ }^{3}$ with a mean disease duration of $7 \cdot 1$ years. ${ }^{4}$

Whilst studies from the USA report that most patients discontinued steroids in less than two years ${ }^{1213}$ with a mean of 11 months treatment, European studies have suggested that most patients require steroids for at least two years. Fourteen to seventeen per cent discontinued steroids at 16 to 21 months ${ }^{4}$ and $40-45 \%$ discontinued treatment between 24 and 31 months. ${ }^{6-10}$ One study found only $16 \%$ of patients had stopped taking steroids at five years. ${ }^{11}$
It is well recognised that relapses, including loss of vision, can occur in patients who are well controlled on corticosteroids. ${ }^{7}{ }^{14}$ The reported incidence of relapse ranges from $4-87 \%$ of patients and many experience more than one episode..$^{\text {8-10 } 1315-19}$ Most relapses were related to steroid reduction $;^{516}$ in one study the disease spontaneously became active. ${ }^{9}$ In two studies patients with PMR tended to have PMR flares ${ }^{1017}$ but in another, $55 \%$ of PMR patients went on to develop GCA and $26 \%$ developed visual or neurological complications. ${ }^{18}$ Other groups reported that patients with either PMR or GCA usually had polymyalgic flares ${ }^{8}$ and that GCA patients had both polymyalgic and arteritic flares. ${ }^{17}$ Most groups agreed that relapses were more common during the first year of treatment. Two studies reported that the ESR was evaluated during $70 \%{ }^{8}$ and $100 \%{ }^{15}$ of relapses. Once treatment was discontinued, the reported relapse rate ranged from 4-43\%. ${ }^{6} 917$ Patients tended to relapse within one year of stopping prednisolone $e^{8917}$ but relapses after 10 years occurred. $^{8}$

There is considerable variation in the reported frequency and nature of relapses. It is not clear why relapses occur, nor whether they can be predicted. The aim of this prospective study was to follow patients with PMR alone, GCA alone and with both conditions and document the course of their disease, with particular emphasis on relapses in each patient subgroup.

\section{Patients and methods}

Seventy four patients with active untreated PMR/GCA were followed up for a median of 60 weeks. All fulfilled the diagnostic criteria of Jones and Hazleman (Appendix). ${ }^{18}$ Patients were allocated by clinical diagnosis as having PMR only, GCA only, or features of both PMR and GCA ('Both'). Patients were reviewed fortnightly initially, then every 2-3 months. On each visit, muscle pain, stiffness or tenderness, headaches, scalp tenderness, temporal artery tenderness, pulsation and thickening and visual symptoms were graded on a scale from $0-2$, and other symptoms or signs also recorded including blood pressure and weight. An overall clinical assessment was then made on each visit as follows: 
Grade 1 - Relapse, either as a new event or if judged to have remained in relapse from the previous visit. Patients experiencing a relapse had developed symptoms and signs which were felt to require an increase in prednisolone dosage. PMR relapse included as a minimum, pain and stiffness in the shoulder of hip girdle; GCA relapse required headache with scalp or temporal artery tenderness noted on examination, or visual symptoms.

Grade 2 - Improvement from Grade 1 but symptoms/signs not fully resolved.

Grade 3 - Well, no significant symptoms/ signs.

\section{INITIAL TREATMENT}

The prednisolone dose was controlled by the doctor not the patient but on some occasions, patients increased the dose of prednisolone between visits if they experienced a relapse. The treatment regime for the first two months has been previously reported. ${ }^{20}$ Patients with GCA took $40 \mathrm{mg}$ prednisolone for five days then were randomly allocated to a low dose regime $(20 \mathrm{mg}$ for four weeks, $15 \mathrm{mg}$ for two weeks then $10 \mathrm{mg}$ for two weeks) or a high dose regime (40 mg for four weeks, $30 \mathrm{mg}$ for two weeks, $20 \mathrm{mg}$ for two weeks).

Patients with PMR were also randomly allocated to a high dose regime $(20 \mathrm{mg}$ prednisolone for one month, $15 \mathrm{mg}$ for two weeks then $10 \mathrm{mg}$ for two weeks) or low dose (10 $\mathrm{mg}$ prednisolone/month, $7.5 \mathrm{mg}$ for two weeks then $5 \mathrm{mg}$ for two weeks).

Steroid reduction was about $2.5 \mathrm{mg} / \mathrm{month}$ from 2-4 months, then about $1 \mathrm{mg} /$ month for 4-12 months and $1 \mathrm{mg}$ every 2-3 months thereafter. The current prednisolone dose and any planned alteration was recorded. Full blood count, ESR (Westergren) C reactive protein (nephelometry), orosomucoid, haptoglobin, $\alpha 1$ antitrypsin, immunoglobulins G, A and $\mathrm{M}$, immune complexes (complement consumption) and alkaline phosphatase were measured on every visit. A record was also kept of patients who relapsed between visits and of intercurrent illness.

STATISTICS

Results were analysed using Chi-squared tests, analysis of variance for the ESR values during relapses and Kruskal Wallis tests for length of follow up, number of visits and steroid dose on relapse in each subgroup.

\section{Results}

Thirty nine patients presented with PMR alone, 18 with GCA alone and 17 with both PMR and GCA ('Both'). Seventeen were male. The mean age was 71.4 years. Sixty nine per cent of patients with PMR presented within four months of onset of symptoms and $65 \%$ of patients with GCA presented within two months of the onset. Fifty per cent of patients with 'Both' presented within four months but almost a third consulted their general practitioners more than a year after disease onset, usually because of the development of GCA symptoms some months after the onset of PMR. GCA preceded PMR in only two patients with both PMR and GCA.

There were 847 patient visits in total, with a range of 2-33 visits/patient (mean 11, SE $0 \cdot 72$ ). The mean length of follow up was similar in all three groups. Two patients $(5 \%)$ with PMR developed GCA after the first two months of treatment; one at 26 weeks and one at 89 weeks (six also developed GCA within the first two months of treatment). ${ }^{20}$ Four patients with GCA developed PMR (24\%) at $15,27,67$ and 75 weeks after starting treatment.

The clinical course within the first two months of treatment has been discussed in a previous paper comparing different steroid regimes. ${ }^{20}$ Two patients were followed up for only eight weeks and one woman with florid GCA died at home at eight weeks. Follow up data was therefore available on 71 patients (39 PMR, 16 GCA, 16 'Both') after two months, with 4729 patient weeks of follow up and 574 patient visits. Patients with 'Both' were reviewed on a mean of ten occasions, PMR 7.5 visits and GCA $7 \cdot 7$ visits. There were 77 observed relapses in 43 patients $(60 \%)$ after the first two months - 24 PMR $(61 \%)$, eight GCA (25\%), 11 'Both' (50\%). Forty one relapses between visits were reported by patients who had increased their prednisolone dose and were well when seen at the next visit. Thus only $27 \%$ of patients did not experience a relapse after the first two months. Most patients $(77 \%)$ were observed to experience one or two relapses after two months but 10 had three or more (table 1 ).

In addition, there were 32 subsequent visits where symptoms remained as severe, that is, 101 Grade 1 visits. There were 74 visits after the initial two months when patients had improved from a relapse but were still not back to normal (Grade 2 visits).

There were significantly fewer abnormal visits (Grade 1 and Grade 2) in patients with GCA only $(p<0.01)$. This difference held when abnormal visits were considered as a percentage of weeks of follow up. If the relapse rate was considered with respect to the final diagnosis rather than the diagnosis on presentation, the same pattern was seen. Four patients (two PMR, two Both) accounted for 60 abnormal visits (Grade 1 and 2) but even if these atypical patients were excluded, patients with GCA alone had the fewest relapses and abnormal visits.

One patient with both PMR and GCA lost the sight in one eye while on treatment; ESR

Table 1 Number of patients in each subgroup who had relapses after two months, shown as number of relapses/ patient

\begin{tabular}{|c|c|c|c|c|}
\hline \multirow[b]{2}{*}{$\begin{array}{l}\text { Number of } \\
\text { relapses }\end{array}$} & \multicolumn{4}{|c|}{ Number of patients } \\
\hline & $\begin{array}{l}P M R \\
(24)\end{array}$ & $\begin{array}{l}G C A \\
(8)\end{array}$ & $\begin{array}{l}\text { BOTH } \\
\text { (11) }\end{array}$ & $\begin{array}{l}A L L \\
(43) \\
\end{array}$ \\
\hline $\begin{array}{l}1 \\
2 \\
3 \\
4+\end{array}$ & $\begin{array}{r}15 \\
3 \\
5 \\
1\end{array}$ & $\begin{array}{l}4 \\
2 \\
1 \\
1\end{array}$ & $\begin{array}{l}5 \\
4 \\
1 \\
1\end{array}$ & $\begin{array}{r}24 \\
9 \\
7 \\
3\end{array}$ \\
\hline
\end{tabular}


Table 2 Frequency of symptoms and signs during relapses in each subgroup

\begin{tabular}{lccccccc}
\hline \multicolumn{7}{c}{ Symptoms/signs-Number of occurrences } \\
\cline { 2 - 8 } & $\begin{array}{l}\text { Muscle } \\
\text { pain }\end{array}$ & $\begin{array}{l}\text { Muscle } \\
\text { stiffness }\end{array}$ & $\begin{array}{l}\text { Muscle } \\
\text { tenderness }\end{array}$ & Headache & $\begin{array}{l}\text { Visual } \\
\text { symptoms }\end{array}$ & $\begin{array}{l}\text { Tender scalp/ } \\
\text { temporal artery }\end{array}$ & Other \\
\hline PMR & 33 & 32 & 19 & 13 & 3 & 10 & 3 \\
GCA & 6 & 4 & 0 & 8 & 1 & 6 & 2 \\
BOTH & 6 & 4 & 2 & 11 & 10 & 7 & 3 \\
ALL & 45 & 40 & 21 & 32 & 14 & 23 & 8 \\
\hline
\end{tabular}

Table 3 Mean prednisolone dosage ( $m g$ ) with time

\begin{tabular}{|c|c|c|c|c|c|c|}
\hline & \multicolumn{2}{|l|}{$P M R$} & \multirow{2}{*}{$\begin{array}{l}\text { Number of } \\
\text { patients }\end{array}$} & \multicolumn{2}{|c|}{$G C A+B o t h$} & \multirow{2}{*}{$\begin{array}{l}\text { Number of } \\
\text { patients }\end{array}$} \\
\hline & Dose & (Range) & & Dose & (Range) & \\
\hline $6 / 12$ & 8.68 & $(5-15)$ & 37 & $10 \cdot 60$ & $(5-20)$ & 26 \\
\hline 1 year & $7 \cdot 10$ & $(2 \cdot 5-12 \cdot 5)$ & 25 & $7 \cdot 38$ & $(2 \cdot 5-15)$ & 21 \\
\hline $18 / 12$ & $5 \cdot 82$ & $(2-15)$ & 14 & $5 \cdot 38$ & $(0-10)$ & 13 \\
\hline 2 years & 6.90 & $(0-20)$ & 9 & 8.05 & $(10-40)$ & 9 \\
\hline 3 years & $7 \cdot 5$ & $(0-20)$ & 3 & $5 \cdot 0$ & $(2 \cdot 5-5)$ & 4 \\
\hline
\end{tabular}

and CRP were normal. One 86 year old patient who presented with loss of vision in one eye and florid GCA on temporal artery biopsy died suddenly at home after eight weeks of treatment; post mortem was not carried out. There were no other serious complications. The most common symptoms during relapses (as a percentage of all symptoms) were muscle pain $(25 \%)$, muscle stiffness $(21 \%)$, headache $(18 \%)$ and temporal artery or scalp tenderness $(13 \%)$. Visual symptoms were blurring of vision and eye pain or transient loss of vision. The frequency with which these occurred in each subgroup is shown in table 2 .

In those patients who had features of PMR and GCA, either initially or during follow up, relapses due to arteritis were more common than polymyalgic flares. Thirty four relapses included arteritic features (15 also with PMR) and in 11 the relapse was PMR alone. The dosage of prednisolone with time is shown in table 3. Two patients with PMR and six with GCA or 'Both' were followed up to 15-21 weeks and are not included in this table.

Fifty four per cent of relapses occurred after reduction of the dose of steroid. The steroid dose at the time of relapse ranged for $5-40 \mathrm{mg}$ prednisolone/day (mean $10 \mathrm{mg}$ ) and was not significantly different in each subgroup. Most relapses occurred within the first year; $50 \%$ were between the third and sixth month (table 4). Relapses usually settled within six weeks but four patients had persisting mild PMR symptoms partly because they preferred to tolerate these rather than increase their steroid dose. No laboratory features appeared to predict relapse; the number of relapses/year

Table 4 Time-point at which new relapses occurred in each subgroup after 2 months

\begin{tabular}{lclll}
\hline \multirow{2}{*}{$\begin{array}{l}\text { Time } \\
\text { (months) }\end{array}$} & $P M R$ & \multicolumn{3}{c}{} \\
\cline { 2 - 5 } & PMR & $G C A$ & BOTH & ALL (\%) \\
\hline $2-3$ & 7 & 3 & 1 & $14 \cdot 3$ \\
$4-6$ & 15 & 4 & 8 & $35 \cdot 1$ \\
$7-9$ & 3 & 1 & 2 & $7 \cdot 8$ \\
$10-12$ & 4 & 1 & 4 & $11 \cdot 6$ \\
$13-18$ & 6 & 3 & 3 & $15 \cdot 6$ \\
$19-24$ & 3 & 2 & 0 & $6 \cdot 5$ \\
$25-30$ & 3 & 1 & 2 & $7 \cdot 8$ \\
$>30$ & 1 & 0 & 0 & $1 \cdot 3$ \\
\hline
\end{tabular}

was not related to the histology on temporal artery biopsy.

No patient with PMR evolved into rheumatoid arthritis during the period of follow up. One patient has subsequently developed seronegative polyarthritis. Possibly the initial strict exclusion of patients with peripheral joint involvement reduced the inclusion of polymyalgia polyarthritis.

Seven patients managed to discontinue steroid treatment. One further patient came off steroids at 70 weeks but had a relapse with features of myalgia and arteritis at 100 weeks. Thus $24 \%$ of patients followed for 18 months to two years had discontinued steroids at a mean cumulative dose of $3 \cdot 16 \mathrm{~g}$. By the end of the study a further 39 patients had exceeded this dose and were still requiring steroids.

The ESR and CRP during follow up have been discussed in an earlier paper; ${ }^{21}$ The ESR was found to correlate better than CRP with relapses. Orosomucoid and haptoglobin levels were slightly elevated during $40 \%$ relapses but in almost half the patients, values were chronically mildly elevated. A minimal increase in $\alpha 1$ antitrypsin was seen in $27 \%$ relapses. Immune complexes were elevated in $10 \%$ of new relapses and alkaline phosphatase was abnormal in only five relapses. Immunoglobulin $G$ was elevated in three relapses, $\operatorname{IgA}$ in one and $\operatorname{IgM}$ in four.

\section{Discussion}

This study suggests that PMR/GCA runs a benign course in most patients but at least one episode or relapse was common. Serious complications were rare. Although $20 \%$ of patients with PMR developed GCA after treatment was started, three quarters did so within the first five weeks. It would be prudent to review patients frequently in the first eight weeks of treatment, so that the development of GCA would be detected rapidly. The low incidence of late development of GCA is reassuring. Definition of relapse is inevitably subjective and in this study a pragmatic view was taken: a recurrence of symptoms severe enough to warrant an increase in prednisolone dose was defined as relapse, irrespective of the ESR or CRP. Almost all patients were directly referred by their general practitioners who would normally have managed at least half of these cases at home. This study therefore is closer to a true population study than most. This may partly account for the lower incidence of serious complications compared with other retrospective studies. A previous study in the same hospital ${ }^{18}$ found a much higher complication rate, probably because it dealt with a selected population many of whom had been seen by physicians, neurologists or ophthalmologists, and who may have had a more aggressive disease.

We confirmed the finding of other studies that relapses were most frequent within the first few months after diagnosis. About half of the relapses occurred in relation to attempted steroid reduction usually at a dose of around $10 \mathrm{mg}$. We suggest that clinicians should 
review patients more frequently when reduction below $10 \mathrm{mg}$ of prednisolone is attempted.

Patients with both GCA and PMR had more frequent relapses and persistence of symptoms, and the difference was most striking when compared with those with GCA only. This has not been documented previously although most studies have not separated GCA alone from GCA with PMR and thus may have missed this observation. These patients were more likely to experience arteritic flares, so the phenomenon of 'pseudorheumatism', seen on steroid reduction, was not the explanation for the increased number of abnormal visits in this group. The number of visits/patient and mean follow up was not significantly different in each subgroup, so these findings are not due to unwell patients being seen more often. The initial response to steroid treatment when higher doses were used was rapid in most cases; relatively small increases in prednisolone dose were given during relapses and it is possible that a larger increase would have led to more rapid recovery. There was no evidence that the different initial treatment regimes influenced relapses later in any subgroup. Some patients, especially those with PMR, preferred to tolerate mild symptoms rather than increase their steroids further.

We examined the data to see if particular characteristics such as age, temporal artery histology, initial ESR or other laboratory features such as, alkaline phosphatase predicted relapse, but found no such association. About a third of patients with 'Both' had symptoms for over a year before treatment; numbers in this group were small and did not appear to be more at risk of relapse.

The acute phase proteins were not of value in assessing disease activity, and the results support an earlier study ${ }^{22}$ where orosomucoid and haptoglobin but not ESR tended to remain elevated despite clinical improvement. Elevation of alkaline phosphatase or immune complexes was rare after treatment was started.

The number of patients able to discontinue steroids was small and could not be formally analysed, but no clinical or laboratory features appeared to predict the early withdrawal of steroids. Our results support the European view that treatment is needed for at least two years in most cases. Longer follow up would be helpful in future studies to clarify the length of treatment needed and the frequency of later relapses.

\section{Appendix}

\section{Diagnostic criteria for PMR/GCA}

\section{Criteria for diagnosis of PMR}

1 Shoulder and pelvic girdle pain which was primarily muscular in the absence of true muscle weakness.

2 Morning stiffness.

3 Duration of at least two months unless treated.
$4 \mathrm{ESR}$ over $30 \mathrm{~mm} / \mathrm{h}$ or C-reactive protein (CRP) over $6 \mu \mathrm{g} / \mathrm{ml}$.

5 Absence of rheumatoid or inflammatory arthritis or malignant disease.

6 Absence of objective signs of muscle disease.

7 Prompt and dramatic response to systemic corticosteroids.

\section{Criteria for diagnosis of GCA}

1 Positive temporal artery biopsy or cranial artery tenderness noted by a physician.

2 One or more of the following: visual disturbance, headache, jaw pain, cerebrovascular insufficiency.

3 ESR over $30 \mathrm{~mm} / \mathrm{h}$ or CRP over $6 \mu \mathrm{g} / \mathrm{ml}$.

4 Response to corticosteroid.

If a patient with PMR receiving corticosteroids developed symptoms of GCA, a raised ESR or CRP was not considered necessary for the diagnosis of GCA.

Bruce W. Senile rheumatic gout. BMF 1988; 2: 811-13.

Hutchinson J. Diseases of the arteries No 1 . On a peculiar form of thrombotic arteritis of the aged which is sometimes productive of gangrene. Archives of Surgery 1890; 2: 323-9.

3 Bagratuni L. Anarthritic rheumatoid disease. Lancet 1956; 2: 694-7.

4 Bagratuni L. Prognosis in the anarthritic rheumatoid syndrome. $B M F$ 1963; 1: 513-8.

5 Fauchald R, Rygrold O, Oystese B. Temporal arteritis and polymyalgia rheumatica. Clinical and biopsy findings. Ann Int Med 1972; 77: 845-52.

6 Myles A B. Polymyalgia rheumatica and giant cell arteritis. Rheum Rehab 1975; 14: 231-5.

7 Sorensen P S, Lorenzen I. Giant cell arteritis, temporal arteritis and polymyalgia rheumatica. Acta Med Scand 1977; 201: 207-13.

8 Bengtsson B E, Malmvall B A. Prognosis of giant cell arteritis including temporal arteritis and polymyalgia rheumatica. Acta Med Scand 1981; 209: 337-45.

9 Behn A R, Perera T, Myles A B. Polymyalgia rheumatica and corticosteroids: how much for how long? Ann Rheum Dis 1983; 42: 374-8.

10 Ayoub W T, Franklin C M, Torretti D. Polymyalgia rheumatica. Duration of therapy and longterm outcome. Amer 7 Med 1985; 79: 309-15.

11 Coomes E N, Ellis R M, Kay A G. A prospective study of 102 patients with polymyalgia rheumatica syndrome. Rheum Rehab 1976; 15: 270-5.

12 Huston K A, Hunder G G. Giant cell (cranial) arteritis: a clinical review. Amer $H \mathcal{F}$ 1980; 100: 99-107.

13 Chuang T-Y, Hunder G G, Ilstrup D M, Kurland L T. Polymyalgic rheumatica. A 10 year epidemiological and clinical study. Ann Int Med 1982; 97: 672-80.

14 Whitfield A G W, Bateman M, Cooke W T. Temporal arteritis. Br f Ophthalmol 1963; 47: 555-66.

15 Paulsen S, Iversen T O. Rheumatic polymyalgia. Longterm treatment with steroids. Acta Rheum Scand 1977; 17; 165-8.

16 Huston K A, Hunder G G, Lie J T, Kennedy R H, Eweback L R. Temporal arteritis. A 25 year epidemiological clinical and pathologic study. Ann Int Med 1978; 88: 162-7.

17 Von Knorring J. Treatment and prognosis in polymyalgia rheumatica and giant cell arteritis. Acta Med Scand 1979; 205: 429-35.

18 Jones J G, Hazleman B L. Prognosis and management of polymyalgia rheumatica. Ann Rheum Dis 1981; 40: 1-5.

19 Knudsen L, Christenson G, Krohn L. Polymyalgia rheumatica syndrome. Scand $\mathcal{f}$ Rheumatol 1982; 11: 117-20.

20 Kyle V, Hazleman B L. Treatment of polymyalgia rheumatica (PMR) and giant cell arteritis (GCA) I steroid regimens in the first 2 months. Ann Rheum Dis 1989; 48: 658-61.

21 Kyle V, Cawston T E, Hazleman B L. Erythrocyte sedimentation rate and $C$ reactive protein in the assessment of polymyalgia rheumatica/giant cell arteritis on presentation and during follow up. Ann Rheum Dis 1989; 48: 667-71.

22 Park J, Jones J, Hazleman B. Relationship of the erythrocyte sedimentation rate to acute phase proteins in polymyalgia rheumatica and giant cell arteritis. Ann Rheum Dis 1981; 40: 493-5. 